Florida International University FIU Digital Commons

$3-3-2011$

\title{
The Role of Perceived Control in the Relation Between Parental Control and Anxiety among Anxious Youth
}

Maria Pienkowski

Florida International University, mpienkow@fiu.edu

DOI: $10.25148 /$ etd.FI12041110

Follow this and additional works at: https://digitalcommons.fiu.edu/etd

\section{Recommended Citation}

Pienkowski, Maria, "The Role of Perceived Control in the Relation Between Parental Control and Anxiety among Anxious Youth" (2011). FIU Electronic Theses and Dissertations. 561.

https://digitalcommons.fiu.edu/etd/561 


\section{FLORIDA INTERNATIONAL UNIVERSITY \\ Miami, Florida}

THE ROLE OF PERCEIVED CONTROL IN THE RELATION BETWEEN

PARENTAL CONTROL AND ANXIETY AMONG ANXIOUS YOUTH

A thesis submitted in partial fulfillment of the

requirements for the degree of

MASTER OF SCIENCE

in

PSYCHOLOGY

by

Maria Pienkowski

2012 
To: Dean Kenneth Furton

College of Arts and Sciences

This thesis, written by Maria Pienkowski, and entitled, The Role of Perceived Control in the Relation Between Parental Control and Anxiety among Anxious Youth having been approved in respect to style and intellectual content, is referred to you for judgment.

We have read this thesis and recommend that it be approved.

$\begin{array}{r}\hline \text { James Jaccard } \\ \hline \text { William Kurties } \\ \hline \text { Wendy K. Silverman, Major Professor }\end{array}$

Date of Defense: March 3, 2011

The thesis of Maria Pienkowski is approved.

Dean Kenneth Furton
College of Arts and Sciences

Florida International University, 2012 


\begin{abstract}
OF THE THESIS
THE ROLE OF PERCEIVED CONTROL IN THE RELATION BETWEEN

PARENTAL CONTROL AND ANXIETY AMONG ANXIOUS YOUTH
\end{abstract}

by

\title{
Maria Pienkowski
}

Florida International University, 2012

Miami, Florida

\section{Professor Wendy K. Silverman, Major Professor}

The purpose of this thesis was to examine potential respective mediating and moderating roles of two types of control variables, locus of control (LOC) and perceived anxiety control (AC), among four different aspects of parenting (i.e., Psychological Control, Intrusiveness, Inconsistency, and Lax Discipline) and anxiety symptoms thereby extending the work of Chorpita et al. (1998) and Muris et al. (2002). Consistent with Chorpita and Barlow (1998), it was hypothesized that for younger children, LOC would mediate the relation between parenting styles and anxiety. For older children, in contrast, LOC would moderate the relation between parenting styles and anxiety. Because this is the first study to include PCA with respect to parenting style and anxiety, no specific hypothesis was formulated regarding its mediating versus moderating role.

Participants consisted of 237 youth ( $49 \%$ girls) and their parents, who were referred to a clinic for anxiety disorders. After signed informed consent/assent was obtained, a comprehensive assessment battery of interview schedules and questionnaires was administered. Data were analyzed using Structural Equation Modeling (SEM) 
procedures and models examining the two types of Child Control as both mediators and moderators were tested.

Results indicated that, contrary to hypotheses, child age did not play a significant role in determining whether LOC operated as a mediator or a moderator. Child Age did, however, play a role in determining whether PCA operated as a mediator for only one of the four parenting styles: Lax Discipline. Specifically, for younger children, PCA did not mediate the relation between Lax Discipline and child anxiety; however, for older children, PCA did mediate the relation between Lax Discipline and child anxiety. Findings indicate that LOC significantly predicts child anxiety. In addition, LOC partially mediates the relation between only one aspect of parenting, Inconsistency, and child anxiety. Greater inconsistency in parenting predicts a more external LOC in the child, which in turn predicts high levels of child anxiety. Perceived AC does not significantly meditate nor moderate the relation between the four different aspects of parenting and anxiety. Furthermore, AC does not significantly predict child anxiety.

Also, contrary to hypotheses, child age does not play a significant role in determining whether LOC operated as either a mediator or a moderator between parenting and child anxiety. Child age, however, does moderate the relation between Lax Discipline and perceived AC, such that the association between Lax Discipline and perceived AC is stronger for older children than younger children.

The results further the empirical evidence that clarifies the roles of "control" and "parenting" in a sample of youth and their parents within the framework. 


\section{TABLE OF CONTENTS}

CHAPTER

PAGE

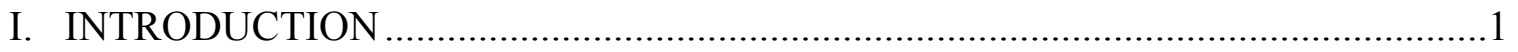

LOCUS OF CONTROL AND ANXIETY ………………………………......2

PERCEIVED CONTROL OVER ANXIETY EVENTS AND ANXIETY .............3

PARENTAL CONTROL, LOCUS OF CONTROL, PERCEIVED CONTROL

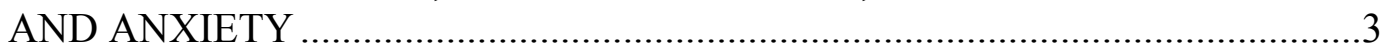

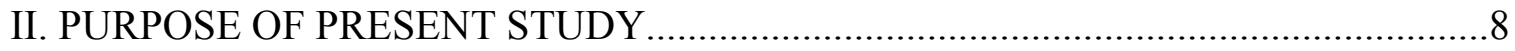

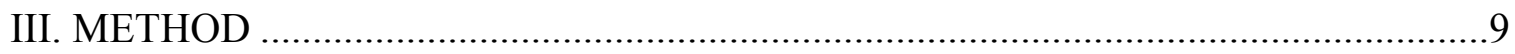

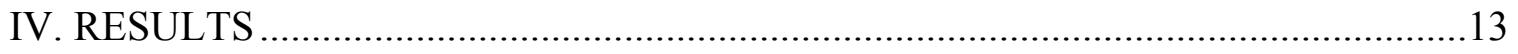

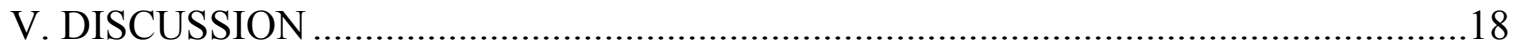

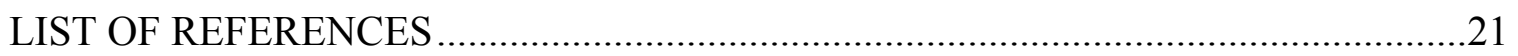




\section{Introduction}

Anxiety disorders are some of the most prevalent disorders of childhood and adolescence (e.g., Costello et al., 1996; Fergusson, Horwood, \& Lynskey, 1993), and are associated with significant interference over various domains of functioning among youth (Dweck \& Wortman, 1982; Last, Hanson, \& Franco, 1997; McGee \& Stanton, 1990; Strauss, Frame, \& Forehand, 1987). Even though anxiety disorders typically abate within three to four years for most youth (Last, Perrin, Hersen, \& Kazdin, 1996), for a significant proportion of these youths, anxiety disorders have either a chronic course or develop into other disorders (e.g., other anxiety and depressive disorders; Keller, Lavori, Wunder, Beardslee, \& Schwartz, 1992; Last et al., 1996; Ollendick \& King, 1994; Orvaschel, Lewinshohn, \& Seeley, 1995). Given the prevalence of anxiety disorders among youth and the related adverse potential outcomes, it is important to investigate factors associated with the expression and development of anxiety in childhood and adolescence. Examining factors associated with anxiety may advance theoretical conceptualizations of anxiety and also inform strategies for the intervention and prevention of anxiety.

Recent theoretical conceptualizations of child psychopathology emphasize the role of control on the expression and development of both anxiety and depression (Barlow et al., 1996; Chorpita \& Barlow, 1998). However, the concept of "control" in existing research has been derived from an assortment of psychological theories. As such, the definition of control in the literature varies according to the conceptual basis of the term (Weems \& Silverman, 2005). In a review of the literature pertaining to the broad conception of "control" and childhood anxiety, Weems and Silverman (2005) attempted 
to clarify the different definitions of "control" and delineated the implications of each type of control on child anxiety.

In this study, we adopted Weems's and Silverman's (2005) categorizations and distinctions between the various types of control and we focus on two in particular. The first is locus of control, which is characterized by the extent to which an individual believes he or she possesses the ability to control reinforcement. An individual with an internal locus of control attributes control over reinforcement (i.e., positive outcomes) to qualities within the self; whereas an individual with an external locus of control attributes control over reinforcement to external factors (Rotter, 1966). The second type of control is perceived control, which involves the individual's perception about the nature of his or her control over situational factors and events. The concept of perceived control involves not only where the control is located (internal versus external), but also what the control is over (e.g., anxious feelings, threatening stimuli).

\section{Locus of Control and Anxiety}

Locus of control as related to anxiety and its disorders among youth has been examined empirically through the use of youth self-report measures of locus of control. Studies examining the relation between locus of control and anxiety have used largely non-clinical samples of youth. These studies have shown that youths' external locus of control beliefs are associated with their self-rated anxiety symptoms $(r=.23$ to .68$)$ (Ollendick, 1979; Rawson, 1992; Sriberg, 1974). Nunn (1988), for example, found that having an external locus of control as measured by the Nowicki Strickland Locus of Control scale (NSLOC; Nowicki \& Strickland, 1973) was significantly correlated with trait anxiety as measured by the State Trait Anxiety Inventory for Children (STAIC; 
Spielberger, 1973) in a nonclinical sample of 267 youth $(\mathrm{r}=.31)$. These results were replicated by St-Yves, Dompierre, Freeston, Jacques, and Malo (1989) using an independent non-clinical sample of 271 youth $(r=.24)$.

\section{Perceived Control over Anxiety Events and Anxiety}

According to Barlow's $(1988 ; 2002)$ model of anxiety, perceived lack of control over "external" threats such as fearful events, objects, or situations and/or lack of control over negative "internal" bodily reactions are directly related to the expression of anxiety. Perceived control over anxiety events also has been examined through the use of youth self-report measures. Using a combined clinic-referred and non-clinical sample of 117 youth, Weems, Silverman, Rapee, and Pina (2003) found a significant negative correlation between youths' perceived control, as measured by the Anxiety Control Beliefs Questionnaire (ACQ; REF) and self-reported anxiety levels, as measured by the Revised Children's Manifest Anxiety Scale (RCMAS; Reynolds \& Richmond, 1978). In addition, Weems et al. (2003) reported that youths'anxiety related control beliefs predicted the presence of an anxiety disorder, even when controlling for anxiety symptoms using the RCMAS (Reynolds \& Richmond, 1978), and locus of control using the NSLOC. It should also be noted that perceived control over anxiety events as measured by the ACQ was correlated with NSLOC scores $(r=.42)$. This finding provides evidence for the notion that although perceived control and locus of control are related, they are indeed distinct constructs.

\section{Parental Control, Locus of Control, Perceived Control and Anxiety}

Theoretical conceptualizations of anxiety development further suggest that certain parenting styles, such as parental control (i.e., parental intrusion and constraint imposed 
on the child's actions) are associated with the expression of youth anxiety (Barlow, 2000; Chorpita \& Barlow, 1998). Rapee (1997) reviewed the literature on parenting and the development of anxiety and depression, and concluded that parental control has been found generally to be...positively and specifically related to later anxiety." Research shows that the same parenting style (i.e., parental control) found to be associated with anxiety also has been found to be associated with the development of control related beliefs in children (e.g., Schneewind, 1995). Specifically, parents who provide opportunities for autonomy and independence and who encourage the development of new skills are more likely to foster internal locus of control beliefs in their children (Chandler, Wolf, Cook, \& Dugovics, 1980; Gordon, Nowicki, \& Wichern, 1981). In a review involving the role of control in the early environment, Chorpita and Barlow (1998) delineated how individuals' experiences with diminished control may foster the development of anxiety. Chorpita and Barlow (1998) defined control as an individual's ability to personally influence events and outcomes in one's environments as related to reinforcement. The authors summarized the research literature to support the notion that parenting style influences a child's development of control. They concluded that parents who are less intrusive and protective, as well as more contingently responsive to their children's behaviors, foster the development of a healthy locus of control in their children (Chorpita \& Barlow, 1998; Barlow, 2000). In addition, Chorpita and Barlow (1998) drew connections between the constructs of parenting styles, perceived locus of control in the child and the development as anxiety. Specifically, they proposed t a model stating that anxiety develops initially as a result of a diminished sense of locus of control, which serves to mediate the relationship between parenting styles and 
anxiety in early development. They further suggested that a moderation model seems to operate in later childhood and adulthood (Cole \& Turner,1993; Hammen, Adrian \& Hiroto, 1988), in which locus of control operates as an amplifier of stressful events rather than a mechanism through which anxiety develops.

Chorpita, Brown, and Barlow (1998) conducted the first empirical investigation of the role of perceived locus of control on the relation between parental control and negative affect (i.e., symptoms of anxiety and depression) with a sample of 62 clinicreferred anxious youth and 31 non-referred youth ( 6 to 15 years; $\mathrm{M}=11.15$ years; $\mathrm{SD}=$ 2.61) and their parents. Using structural equation modeling (SEM), Chorpita et al. (1998) tested a model hypothesizing that youth-rated locus of control (NSLOC; Nowicki \& Strickland, year) would mediate the relation between youth and parent rated control in the family environment (Control subscale of the Family Environment Scale, FES; Moos, 1986) and youth and parent rated negative affect (Children's Depression Inventory [CDI], Kovacs, 1981; Revised Children's Manifest Anxiety Scale [RCMAS], Reynolds \& Richmond, year; and the Internalizing scale of the Child Behavior Checklist [CBCL], Achenbach, 1991) among youth.

Results supported the hypothesized mediational model described above. High levels of youth control in the family environment predicted high levels of perceived external locus of control in youth, which in turn predicted high levels of negative affect. Negative affect, in turn predicted clinician severity ratings of youth anxiety and depressive disorders as measured by the Clinician Severity Rating scale (CSR; Silverman \& Albano, 1996). 
Muris, Meesters, Schouten, and Hoge (2002) examined the role of perceived control on the relation between perceived parental rearing behaviors (i.e., overprotection, anxious rearing, rejection, and emotional warmth) and symptoms of anxiety and depression in a sample of 167 non-clinical youth ages 11 to 14 years old $(\mathrm{M}=12.18$ years; $\mathrm{SD}=.47)$. Whereas Chorpita et al. (1998) examined only the mediating role of perceived locus of control on the relation between parental rearing behaviors (i.e., controlling family environment) and symptoms of negative affect (i.e., symptoms of anxiety and depression), Muris et al. (2002) examined both the mediating and moderating role of perceived control (using the Perceived Control Scale [PCS]; Weisz et al., 1998) on the relation between perceived parental rearing behaviors (using the child version of the Egna Minnen Betraffende Uppfostran [EMBU-C] or "my memories of upbringing;" Castro et al., 1993) and self-rated symptoms of anxiety and depression (using the Revised Children's Anxiety and Depression Scale [RCADS]; Chorpita et al., 2000), respectively. The measure of perceived control in this study assessed youth perception of locus of control (i.e., internal or external) over academic, social and behavioral outcomes.

Results of hierarchical regression analyses did not support a mediating role of perceived control on perceived parental rearing behaviors and symptoms of anxiety and depression. Instead, results provided evidence for a moderating role of perceived control on the relation between parental rearing, specifically anxious rearing, and anxiety symptoms. Thus, the interaction between high levels of perceived anxious rearing and low levels of perceived control was associated with high levels of anxiety symptoms. Although Chorpita et al.'s (1998) findings point to perceived locus of control, as measured by the NSLOC, as a mediator of the relation between parental control and 
negative affect, the results of Muris et al. (2002) designate perceived control, as measured by the PCS, as a moderator of the relation between parental rearing and anxiety symptoms. The inconsistent findings across these two studies may be due to a variety of factors including methodological differences, such as differences in the constructs of interest, locus of control versus perceived control over academic, behavioral and social outcomes (e.g., NSLOC versus PCS), sample characteristics (e.g., mixed clinical and non-clinical versus non-clinical youth), and data analytic techniques (e.g., SEM versus hierarchical regression analyses). Furthermore, the age range of the samples used in Chorpita et al. (1998) and Muris et al. (2002) differ in terms of variability. In Chorpita et al. (1998) the sample consisted of youth with a broad age range $(\mathrm{M}=11.15$ years, $\mathrm{SD}=$ 2.61, range 6-15 years), in Muris et al. (2002) the sample consisted of youth with a smaller age range $(\mathrm{M}=12.18$ years, $\mathrm{SD}=0.47$, range $11-14$ years $)$. Muris et al. $(2002)$ suggested that the fact that younger children were included in the analyses conducted by Chorpita et al. (1998) might have contributed to the finding of a mediational effect.

As sly noted, Chorpita and Barlow (1998) posited a mediational role of perceived locus of control in younger children, and a moderational role of perceived locus control in older children. Thus, the possibility remains that the age of the child may play a significant role in determining the effects of locus of control and perceived control on the relation between parenting and anxiety. Neither Chorpita et al. (1998) nor Muris et al. (2002) statistically evaluated whether the mediating and/or moderating role of locus of control or perceived control varied as a function of youth age. Thus, it remains unclear what the role of control is in the relation between parental control and anxiety among younger and older youth. 


\section{Purpose of Present Study}

The purpose of the present study is to extend the past findings of Chorpita et al. (1998) and Muris et al. (2002). In a sample of clinic referred anxious youth, it was of interest to examine age as a variable that might influencing the mediating and/or moderating role of youths' ratings of perceived locus of control and youths' ratings of perceived control over anxiety related events on the relation between youths' perceived parental control and self-rated anxiety symptoms. It was hypothesized that for younger children, youths' ratings of locus of control would mediate the relation between youths' ratings of parental control and anxiety symptoms. Specifically, high levels of youth perceived parental control will influence youths' ratings perceived external locus of control among youth, which will contribute to high levels of youth self-rated anxiety symptoms. It also was hypothesized that for older children, youths' ratings of locus of control would moderate not mediate the relation between youth perceived parental control and anxiety symptoms. Specifically, the interaction between youths' perceived external locus of control among youth and high levels of youths' perceived parental control would contribute to high levels of youth self-rated anxiety symptoms (controlling for symptoms of depression).

Another way in which the current study extends past work is its examination of specific types of parenting styles as they relate to both types of control and anxiety. In past work (Chorpita et al., 1998, Muris et al., 2002), the authors used a general measure of parental control in determining the effects of parental control on child perceived locus of control/perceived control and subsequent anxiety. However, the theories connecting parental control to child control and anxiety speak of more specific parenting styles 
involving intrusiveness, inconsistency and overprotection. The current study thus examined the effects of four specific types of parenting, as reported by youth, : control, intrusiveness, inconsistency, and lax discipline, as measured by the CRPBI108(Schuldermann \& Schuldermann, 1970) on youth control and anxiety.

The final way the e current study extends past work is its y examination of youth's ratings perceived control over anxiety related events, as a moderator and/or mediator of parental control and anxiety. Although Muris et al. (2002) examined perceived control over specific domains, none of the domains measured were anxiety related. Youths' ratings of perceived control over anxiety events as discussed in Barlow's theory of anxiety $(1988,2002)$ seems to be measured better by the ACQ, which asks youths to rate their perceived control over external threats and internal reactions. While studies have s found a significant positive correlation between perceived control over anxiety events (; Rapee, 1996; Weems et al., 2003) and anxiety, this specific construct has yet to be examined as a mediator or moderator of parenting and anxiety. As such, the current study's analyses regarding the role youth reported perceived control over anxiety events as a mediator/moderator of parenting style was viewed as exploratory.

\section{Method}

\section{Participants}

Participants were f 237 youth ( $49 \%$ girls) who were referred to a childhood anxiety disorders specialty clinic and their parents. Their ages were: 7 to 15 years $(M=$ 10.16 years, $S D=2.15$ ). The the participants ethnicity consisted of the following groups: 59\% Hispanic/Latino; 26\% European-American; 3\% African-American; 6\% other ethnic backgrounds; $6 \%$ not reported. The family income levels were as follows: 
$19 \%(<\$ 20,000) ; 23 \%(\$ 20,001-\$ 40,000) ; 39 \%(>\$ 40,001) ; 19 \%$ not reported. The most prevelant anxiety disorder diagnoses were as follows: Separation Anxiety Disorder (SAD) (27\%); Specific Phobia (SOP) (26\%); Generalized Anxiety Disorder (GAD) (19\%); and Social Phobia (SP) (16\%); 75\% had at least one comorbid diagnosis.

The youth were referred to a child anxiety disorders specialty research clinic due to difficulties with excessive fear and/or anxiety. Primary referral sources were school counselors, psychiatrists, pediatricians, and other mental health professionals. All youth met DSM-IV criteria for a primary anxiety disorder diagnosis based on the Anxiety Disorders Interview Schedule for DSM-IV: Child and parent versions (ADIS-IV: C/P; Silverman \& Albano, 1996). Exclusionary criteria for participation in this study were developmental delays (e.g., Asperger's syndrome, mental retardation, autism) or severe psychopathology (e.g., schizophrenia). This screening was done using a standard telephone screen within the Center as well as in the screening sections of the ADIS-C/P. In terms of primary diagnoses, $24 \%$ of youth met criteria for SAD; $22 \%$ met criteria for SP; $17 \%$ met criteria for GAD; $13 \%$ met criteria for SOP; and $1 \%$ met criteria for obsessive compulsive disorder.

\section{Diagnostic Interview Schedule}

Anxiety Disorders Interview Schedule for DSM-IV: Child and Parent Versions (ADIS-C/P for DSM-IV: Silverman \& Albano, 1996). The ADIS-C/P (for DSM-IV) is a semi-structured interview designed specifically for the diagnosis of anxiety disorders in children and adolescents and other related disorders (e.g., affective and externalizing disorders). Information for deriving diagnoses is delineated in the ADIS-IV: C/P guide (Albano \& Silverman, 1996). The ADIS-C/P is a reliable diagnostic instrument for 
deriving anxiety disorder diagnoses in youth. Silverman, Saavedra, and Pina (2001) found test-retest kappa coefficients for the composite diagnoses of SAD, SOP, SP and GAD to be in the excellent range, with $\kappa$ values ranging from 0.80 to 0.92 .

\section{Measures}

Anxiety Control Questionnaire for Children (ACQ-C; Weems et al.Silverman, Rapee, \& Pina, 2003). The ACQ-C was adapted from the Anxiety Control Questionnaire (ACQ; Rapee, Craske, Brown, \& Barlow, 1996) used with adults. The ACQ-C consists of 30 questions that assess perceived lack of control over anxiety related external threats (e.g., fear provoking objects, events, or situations) and negative emotional bodily reactions associated with anxiety (e.g., fast-beating heart, shaking). Youth rate their agreement with each question along a scale of 0 (none) to 4 (very very much). The ACQ contains two control subscales - an internal reactions and external reactions subscale. For this study, the total score was used. The total score ranges from 0 to 120 with lower scores indicating less control over anxiety related threats. Weems et al. (2003) found internal consistency to range from 0.86 to 0.93 for the total scale and subscales of the ACQ-C.

Children's Depression Inventory (CDI; Kovacs, 1992). The CDI is a 27-item self report measure design to assess cognitive, behavioral, and affective symptoms of depression. Each item consists of three statements of different severity ratings and requires the child to choose one statement that best describes him or her. Each item is scored from 0 to 2 and the sum of all the items yields the total CDI score. Scores can range from 0 to 54 , with higher scores indicating more depressive symptoms. Internal consistencies of the CDI have been reported as ranging from 0.83 to 0.89 ; test-retest 
reliabilities have been reported as ranging from 0.74 to 0.77 (Smucker, Craighead, Craighead, \& Green,1986). The CDI has been found to discriminate between psychiatric and non-clinic samples; the CDI also has been found to correlate with clinicians' independent global depression ratings (e.g., r = 0.55; Kovacs, 1992).

Child Report of Parental Behavior Inventory (CRPBI: Schaefer, 1965). The CRPBI assesses youths' perceptions of their mother's controlling behavior toward them. The present study employed the 30-item version, which is comprised of four subscales lax discipline, intrusiveness, general control and inconsistent parenting. Alpha coefficients of internal consistency for these subscales have ranged from 0.62-0.85 (Hill, Bush, \& Roosa, 2003' Knight, Virdin, \& Roosa, 1994; Taylor, Roberts \& Jacobson, 1997).

Nowicki-Strickland Locus of Control Scale (NSLOC: Nowicki \& Strickland, 1973). The NSLOC is a 40-item youth self report measure designed to assess the degree of perceived control over contingent stimuli in the environment (e.g., success or failure). Items are scored 0 or 1 and are summed to yield a total score. The total score ranges from 0 to 40 , with higher scores indicating a greater external locus of control. Nowicki and Strickland (1973) found the NSLOC had adequate test-retest reliability $(r=0.63)$ and internal consistency $(r=.63)$ Revised Children's Manifest Anxiety Scale (RCMAS; Reynolds \& Richmond, 1978). The RCMAS is a 37-item self report measure designed to assess the presence of cognitive, behavioral, or affective symptoms of anxiety and negative affect. The items are dichotomous (i.e., yes or no) and are scored by summing the number of "yes" responses. Total scores range from 0 to 28, with higher scores indicating greater anxiety levels. Pela and Reynolds (1982) reported a 3-week interval 
test-retest reliability of 0.98 . Estimates of concurrent validity for the RCMAS have been found to range from (rs) 0.65 to 0.76 (Lee, Piercel, Friedlander, \& Collamer, 1988).

\section{Procedure}

Parents first contacted the clinic via telephone and were administered a screen by a staff member at the clinic. After the screen was completed it was determined, based on the child's presenting problem, if parents were going to be called to schedule an initial evaluation. If the child's presenting problem was not anxiety-related the family was referred to other mental health centers in the community. When families arrived at the clinic, they signed informed consent forms for participation in the study. Once signed informed consent from parents and signed assent from youths were obtained, a comprehensive assessment battery consisting of interview schedules and questionnaires was administered. When the ADIS-IV: C was administered to youths, parents were administered the questionnaires. When the ADIS-IV: C was finished, parents were administered the ADIS-IV: P and youths were administered the questionnaires.

\section{Results}

Preliminary Analysis Model-based outlier analyses were undertaken prior to all major analyses. Outliers were evaluated using a limited information approach. There were no outliers found. Multivariate was normality evaluated using Mardia's index. The multivariate kurtosis score was significant $(\mathrm{p}<0.05)$.

Examination of univariate indices of skewness and kurtosis within each group revealed no skewness values greater than an absolute value of 1.3 . There were, however, kurtosis values greater than an absolute value of 1.96 indicating non-normality present for only interaction term in model. To account for the non-normality present in the data, structural 
equation modeling (SEM) analyses were pursued in AMOS by using an estimator (MLR) robust to violations of normality based on the Huber-White algorithm.

Missing data. Missing data bias was assessed and no meaningful or significant bias was observed. For the few cases where missing data occurred, values were imputed using the Expectation-Maximization method (King, Honaker, Joseph \& Scheve, 2001) using Amelia (Honaker, Joseph, King, Scheve \& Singh, 2003).

The means, standard deviations, and correlations among all variables present in the model are presented in Table 1. The data were analyzed using structural equation modeling (SEM). Due to the complexity of modeling interactions with SEM, age was first evaluated within the context of the model using a limited information estimation approach (Edwards \& Lambert, 2007).

Youth Perceived Anxiety Control and Youth Perceived Locus of Control as Mediators and/or Moderators The model examining two types of child control as both mediators and moderators was evaluated with AMOS 7.0 using the sample covariance matrix as input and maximum likelihood solution. All non-significant interactions were removed from final model. Because of non-normality present, the model was evaluated using bootstrapping with 2000 bootstrap replicates. Results of both analyses yielded comparable conclusions. Results reported here are from bootstrap analyses. The model is statistically over-identified.

Interaction effects in the SEM analyses were modeled using product terms, as discussed in Jaccard, Turrisi, and Wan (1990) and Jaccard and Wan (1996). These paths reflect differential effects of age, and locus of control on the mediators on the outcome. Given the addition of these product terms in the model, all continuous variables were 
mean centered for ease of interpretation of path coefficients (see Jaccard \& Turrisi, $2003)^{1}$

Following recommendations of Bollen and Long (1993), set of global fit indices were used, including indices of absolute fit, indices of relative fit and indices of fit with a penalty function for lack of parsimony. These include the traditional overall chi square test of model fit (which should be statistically non-significant), the Root Mean Square Error of Approximation (RMSEA; which should be less than .08 to declare satisfactory fit), and $p$-value for tests of close-fit ( $p>.05)$.the Comparative Fit Index (CFI; which should be greater than 0.95$)$. According to these recommendations, the model yielded an excellent fit to the data. The p-value for the Bollen-Stine bootstrapped $\chi 2$ test was .16 . The RMSEA was .04. The p-value for the test of close fit was .53. The CFI was .99 and the GFI was .99. Inspection of residuals showed no significant points of ill-fit in the model and no theoretically meaningful modification indices greater than 3.84 .

Figure 1 shows relevant path coefficients obtained from the model. The residuals indicate the proportion of unexplained variance in the endogenous variables. The variables in the model were able to account for $18 \%$ of variance in locus of control, $9 \%$ of variance in child anxiety control, and $60 \%$ of variance in child anxiety. Youth sex and youth depression were covaried out of the model.

Youth age. Youth age did not play a significant role in determining whether perceived child locus of control and perceived child anxiety control operated as a mediator or a moderator between perceived parental control and child anxiety $(\mathrm{p}>.05)$. Child age moderated the association between Lax Discipline and Youth Anxiety Control. Specifically, Lax Discipline did not significantly predict Youth Anxiety Control when 
youth age was at its mean, but age increased, on the effect of Lax Discipline on Youth Anxiety Control decreased. The final model (see Figure 1) therefore only included youth age as it interacted with Lax Discipline to predict Youth Anxiety Control and as a covariate predicting Youth Anxiety scores.

Parental Control As Figure 1 shows, parental control predicted youth external locus of control. For every one unit increase in parental control, locus of control decreased by .09 units, indicating a more internal locus of control $(B=-.090, \mathrm{SE}=.039$, $\mathrm{p}<.05)$ Parental control did not, however, predict youth anxiety control $(\mathrm{B}=-.004$, $\mathrm{SE}=.039, \mathrm{p}>. .05)$ The total effect was -0.051 . Also, parental control did not statistically predict the youth anxiety scores $(\mathrm{B}=-.031, \mathrm{SE}=.049, \mathrm{p}>.05)$.

Parenting Styles Intrusive parenting did not predict statistically significant change for any of the endogenous variables (i.e., youth locus of control, youth anxiety control, youth anxiety). Intrusive youth anxiety control $(B=.-.023, S E=.257, p>.1,95 \%$ $\mathrm{CI}=?$ ? $)$, or youths self-reported anxiety score $(\mathrm{B}=-.042, \mathrm{SE}=.048, \mathrm{p}>.1)$

As Figure 1 shows, inconsistent parenting predicted a lower score on youth locus of control for children $(B=-.12)$ controlling for age and gender. For every one unit increase in inconsistent parenting, the locus of control decreased by .12 units indicating a higher? more internal locus of control. However, inconsistent parenting did not predict statistically significant change in youth perceived anxiety control $(\mathrm{B}=-.025, \mathrm{SE}-=.219$, $\mathrm{p}>$.1). Inconsistent Parenting did predict lower total anxiety scores. For every one unit increase in Inconsistent Parenting, total anxiety scores went down .073 units. $(B=-.073)$.

As Figure 1 indicates, Lax Discipline predicted Youth Anxiety Control ( $\mathrm{B}=-.350$, $\mathrm{SE}=.210, \mathrm{p}<.1,95 \% \mathrm{CI}=? ?)$ such that more Lax Discipline predicted less Youth Anxiety 
Control. For every one unit increase in Lax Discipline, Youth Anxiety decreased .350 units. Lax Discipline did not predict Locus of Control nor did it predict total Youth Anxiety.

Locus of Control Locus of Control predicted higher total anxiety for youth, controlling for age and gender $(\mathrm{B}=.33 \mathrm{SE}=.085, \mathrm{p}<.001)$. For every one unit increase in Locus of Control, Child Anxiety increased .33 units. This shows that youth's Locus of Control partially mediates the relationship between Inconsistent Parenting and the Youth Anxiety. Youth Locus of Control also played a significant role in determining whether Lax Discipline predicted child anxiety $(\mathrm{p}<.05)$. This indicates that locus of control partially mediates the relationship between Lax Discipline and Youth Anxiety. Additionally, locus of control played a significant role in determining whether Inconsistent Parenting predicted Youth Anxiety $(\mathrm{p}<.05)$.

Youth Anxiety Control. Youth Anxiety Control predicted Youth Anxiety such that the higher the Youth Anxiety Control, the lower the Youth Anxiety. For every one unit increase in Youth Anxiety Control, Youth Anxiety decreased by .25 units. ( $B=-.025$, $\mathrm{SE}=.012, \mathrm{p}<.05,95 \% \mathrm{CI}=? ? ?)$. This finding shows that Youth Anxiety Control partially mediates the relationship between Lax Discipline and Youth Anxiety. The total effect was -.0 .359 .

Interaction Effects. As seen in Figure 1, significant interactions effect were identified. The path from Inconsistent Parenting to Youth Anxiety was moderated by Youth Locus of Control $(\mathrm{B}=.03, \mathrm{p}<.05)$. The path from Lax Discipline to Youth Anxiety was also moderated by Youth Locus of Control $(\mathrm{B}=-.02, \mathrm{p}<.05)$. The interaction was only significant at the mean $(\mathrm{B}=.153, \mathrm{p}<.05)$. The path from Lax Discipline to Youth Anxiety 
Control was moderated by Youth Age $(\mathrm{B}=.24, \mathrm{p}<.05)$.. As age increased, the assocation between Lax Discipline and Youth Anxiety Control decreased.

\section{Discussion}

The study's findings partially supported the model proposed by Chorpita and Barlow (1998) in that youth locus of control mediated the relation between parental control and youth anxiety. High parental control was associated with a more internal locus of control, which subsequently predicted more youth anxiety However, the model proposed by Chorpita and Barlow (1998) indicated that increased parental control leads to a more external locus of control in youth. The study's findings are inconsistent as compared to Chorpita and Barlow's (1998) model, in that parental control did not predict external control. The lack of support for this aspect of Chorpita and and Barlow's model (1998) could be accounted for by suppressor effects. Suppressor effects are defined as, "the amount of decline in linear correlation of two variables by suppressor" (Cohen, Cohen, West, and Aiken (2003). The independent variable, parent control, was correlated with a suppressor variable, perhaps common items on the parental control and locus of control measures; and both are causes of the dependent variable, locus of control.

Youth Locus of Control partially mediated the relation between only one aspect of parenting (i.e., Inconsistency) and youth anxiety. As inconsistent parenting increased, youth ild locus of control became more internal. In turn, youth locus of control predicted high youth anxiety. Although it is theoretically consistent Chorpita \& Barlow (1998) that a more external locus of control accounts for an increase in child anxiety, it is not consistent with Chorpita \& Barlow's (1998) model that inconsistent parenting would predict a more internal locus of control. Suppression could account for this theoretical 
inconsistency as well. Inconsistent parenting was also related to decreased youth anxiety. This could indicate that in a sample of youth with anxiety disorders, inconsistent parenting could improve youth anxiety outcomes relative to the other parenting styles. The separate relationship between inconsistent parenting and child anxiety was moderated by locus of control. That is, for every unit youth locus of control increased, the relation between youth inconsistent parenting and anxiety increased .03 units. More external locus of control in youth was therefore associated with strengthening the anxiety increasing impact of an inconsistent parenting style.

Youth anxiety control was found to partially mediate the relation between the Parent Lax Discipline parenting and youth anxiety. An increase in lax discipline was associated with decreased the child's control over anxiety related events. Again, suppressor effects could be operating: The path between lax discipline and child anxiety control could be accounted for by suppressor effects, similar to the paths from parental control and inconsistent parent to youth locus of control. An increase in youth anxiety control decreased child anxiety, which is consistent with previous literature. Locus of control moderated the relationship between lax discipline and child anxiety. As locus of control becomes more external, the effect of lax discipline on youth anxiety goes down.

Contrary to Chorpita and Barlow's (1998) hypothesis, no support was found for the moderational role of child age in the relations among parenting, locus of control, perceived child anxiety control, and child anxiety. Child age did not play a significant role in determining whether LOC operated as either a mediator or a moderator between parenting and child anxiety. Child age, however, did moderate the relation between Lax Discipline and perceived AC. As child age increases, the relationship between Lax 
Discipline and Child Anxiety Control increases. This indicates that as children get older the effect of lax discipline on increased anxiety control increases.

The model could be improved by the addition of a path from child anxiety as measured by the RCMAS to a measure of clinical impairment. Children who have controlling parents in turn have a more external locus of control. The external locus of control implies a perception of lack of mastery over their environment by fostering a cognitive bias typified by perceiving events as out of one's control (Chorpia \& Barlow, 1998). This lack of mastery then contributes to high trait anxiety. High trait anxiety can cause clinically significant interference in children by causing personal distress, interference in school, problems with friends and interference in family life.

The study has several limitations worth noting. . It employed a cross-sectional design, which limits the ability to draw causal inferences. . Longitudinal studies are warranted to identify causal relations among these variables. Also, only child self-report of parenting, control and anxiety were used. Use of multiple informants' reports and behavioral observations would be important for future work.

\section{LIST OF REFERENCES}

Achenbach, T. M. (1991). Manual for the Child Behavior Checklist and Revised Child 
Behavior Profile (Revised). Department of Psychiatry, University of Vermont, Burlington.

Bollen, K.A. and J.S. Long (eds). 1993. Testing Structural Equation Models. Newbury Park, CA: Sage.

Chorpita, B. F., \& Barlow, D. H. (1998). The development of anxiety: The role of control in the early environment. Psychological Bulletin, 124, 3-21. doi: 10.1037/00332909.124.1.3

Chorpita, B.F., Brown, T.A., \& Barlow, D.H. (1998). Perceived control as a mediator of family environment in etiological models of childhood anxiety. Behavior Therapy, 29, 457-476. doi:10.1016/S0005-7894(98)80043-9

Costello, E. J., Egger, H. L., Copeland, W., Erkanli, A. \& Angold, A. (in press). The developmental epidemiology of anxiety disorders: Phenomenology, prevalence, and comorbidity. In W. K. Silverman \& A. Fields (Eds.), Anxiety disorders in children and adolescents: Research, assessment, and intervention (pp.??). Cambridge University Press.

Jaccard, J., \& Wan, C. (1996). LISREL analyses of interaction effects in multiple regression. Newbury Park, CA: Sage.

Jaccard, J., Turrisi, R., and Wan, C. (1990) Interaction effects in multiple regression. Newbury Park: Sage.

Jaccard, J., \& Turrisi, R. (2003). Interaction effects in multiple regression (2nd ed.). Thousand Oaks, CA: Sage.

Kovacs, M. (1992). Children's Depression Inventory Manual. New York: Multi-Health Systems.

Last, C. G., Perrin, S., Hersen, M., \& Kazdin, A. E. (1996). A prospective study of childhood anxiety disorders. Journal of the American Academy of Child and Adolescent Psychiatry, 35, 1502-1510.

Muris,P., Meesters, C., Schoten, E., \& Hoge E. (2003). Effects of perceived control on the relationship between perceived parental rearing behaviors and symptoms of anxiety and depression in nonclinical preadolescents. Journal of Youth and Adolescence, 33, 51-58. doi: 10.1023/A:1027334314021

Rapee, R. M. (1997). Potential role in childrearing practices in the development of anxiety and depression. Clinical Psychology Review, 17, 47-67. doi:10.1016/S0272-7358(96)00040-2 
Reynolds, C. R., \& Richmond, B. O. (1978). What I think and feel: A revised measure of children's manifest anxiety. Journal of Abnormal Child Psychology, 6, 271-280.

Silverman, W. K., \& Albano, A. M. (1996). Anxiety Disorders Interview Schedule for Children-IV (Child and Parent Versions). San Antonio, TX: Psychological Corporation.

Silverman, W. K., Saavedra, L. M., \& Pina, A. A. (2001). Test-retest reliability of anxiety symptoms and diagnoses with the Anxiety Disorders Interview Schedule for DSM-IV: Child and Parent Versions. Journal of the American Academy of Child and Adolescent Psychiatry, 40, 937-944. 
Table 1. Means, Standard

Deviations and Correlations of

Relevant Variables

\begin{tabular}{llllllllll}
$\mathrm{M}$ & $\mathrm{S} \mathrm{D}$ & 1 & 2 & 3 & 4 & 5 & 6 & 7 & 8 \\
\hline
\end{tabular}

\begin{tabular}{|c|c|c|c|c|c|c|c|c|c|c|c|c|c|c|}
\hline 1. C R P B I - C O N & 19.31 & 5.25 & -- & & & & & & & & & & & \\
\hline 2. CRPB I - IN TR & 18.78 & 5.37 & 0.52 & ${ }^{* *}$ & -- & & & & & & & & & \\
\hline 3. CRPBI - IN CON & 24.59 & 6.00 & 0.26 & ${ }^{* *}$ & $0.31^{* *}$ & -- & & & & & & & & \\
\hline 4. C R P B I - L A X D & 23.78 & 5.95 & 0.04 & & 0.11 & 0.28 & ** & -- & & & & & & \\
\hline 5. N S L O C & 9.12 & 3.60 & -0.27 & ${ }^{* *}$ & $-0.24^{* *}$ & -0.33 & $* *$ & -0.02 & & -- & & & & \\
\hline 6. A C Q & 65.07 & 22.87 & 0.03 & & -0.10 & 0.02 & & -0.13 & $* *$ & $-0.27^{* *}$ & -- & & & \\
\hline 7. R C M A S & 12.46 & 6.50 & -0.06 & & -0.06 & -0.28 & $* *$ & 0.18 & ** & $0.46^{* *}$ & -0.36 & $* *$ & -- & \\
\hline 8. A G E & 9.90 & 8.16 & 0.27 & ${ }^{* *}$ & 0.09 & 0.10 & $* *$ & 0.13 & ** & $-0.23^{* *}$ & 0.07 & $* *$ & -0.02 & -- \\
\hline
\end{tabular}

Note: C R P B I = Children's R ating of Parental Behavior Index; CON $=\mathrm{Control}$; IN T R = Intrusive;

IN C O N = Inconsistency; LAXD

$=\mathrm{Lax} \mathrm{D}$ iscipline; $\mathrm{ACQ}-\mathrm{C}=$

Anxiety Control Questionnaire for Children; NSL OC = N ow ickiStrickland Locus of Control;

R C M A S $-\mathrm{C}=\mathrm{Revised} \mathrm{Children's}$ 
Table 2

\section{Regression Weights:}

\begin{tabular}{|c|c|c|c|c|c|c|}
\hline & & Estimate & S.E. & C.R. & $\mathrm{P}$ & Label \\
\hline NSLOCPRT_MC & $<---C C O N T R O L \_M C$ & -.090 & .039 & -2.314 & .021 & \\
\hline ACQCT_MC & $<---C C O N T R O L \_M C$ & -.004 & .268 & -.014 & .989 & \\
\hline NSLOCPRT_MC & $<---C I N T R U S I$ MC & -.016 & .039 & -.407 & .684 & \\
\hline ACQCT_MC & <---CINTRUSI_MC & -.023 & .257 & -.090 & .928 & \\
\hline NSLOCPRT_MC & $<--$ CICONSIS_MC & -.120 & .033 & -3.618 & $* * *$ & \\
\hline ACQCT_MC & <---CICONSIS_MC & -.025 & .219 & -.113 & .910 & \\
\hline ACQCT_MC & <---CLAXDIS_MC & -.350 & .210 & -1.666 & .096 & \\
\hline NSLOCPRT_MC & $<--$ CLAXDIS_MC & .004 & .032 & .113 & .910 & \\
\hline ACQCT_MC & $<---\operatorname{sex}$ & 9.472 & 2.639 & 3.590 & $* * *$ & \\
\hline ACQCT_MC & $<---A G E \_M C$ & 1.304 & .652 & 2.001 & .045 & \\
\hline ACQCT_MC & $<---$ LAXD_Age & .237 & .091 & 2.610 & .009 & \\
\hline CDI_T_MC & $<---$ NSLOCPRT_MC & .800 & .114 & 7.003 & $* * *$ & \\
\hline CDI_T_MC & $<---$ ACQCT_MC & -.107 & .017 & -6.339 & $* * *$ & \\
\hline CDI_T_MC & $<---$ LAXD_LOC & .042 & .015 & 2.929 & .003 & \\
\hline CDI_T_MC & <---CLAXDIS_MC & .272 & .059 & 4.641 & $* * *$ & \\
\hline CDI_T_MC & <---CICONSIS_MC & -.208 & .062 & -3.349 & $* * *$ & \\
\hline CDI_T_MC & <---CINTRUSI_MC & .152 & .071 & 2.142 & .032 & \\
\hline CDI_T_MC & $<---$ CCONTROL_MC & .154 & .074 & 2.076 & .038 & \\
\hline CDI_T_MC & $<---\mathrm{AGE} \_\mathrm{MC}$ & .460 & .186 & 2.474 & .013 & \\
\hline RCMAS_CT_MC & C<---NSLOCPRT_MC & .334 & .085 & 3.921 & $* * *$ & \\
\hline RCMAS_CT_MC & C<---ACQCT_MC & -.025 & .012 & -2.060 & .039 & \\
\hline RCMAS_CT_MC & C<---CCONTROL_MC & -.031 & .049 & -.633 & .527 & \\
\hline RCMAS_CT_MC & C<---CINTRUSI_MC & -.042 & .048 & -.863 & .388 & \\
\hline RCMAS_CT_MC & C---CICONSIS_MC & -.073 & .043 & -1.718 & .086 & \\
\hline RCMAS_CT_MC & C<--- CLAXDIS_MC & .029 & .041 & .702 & .482 & \\
\hline RCMAS_CT_MC & C<---INCON_LOC & .034 & .012 & 2.941 & .003 & \\
\hline RCMAS_CT_MC & C<---LAXD_LOC & -.023 & .011 & -2.033 & .042 & \\
\hline RCMAS_CT_MC & C<---CDI_T_MC & .498 & .040 & 12.365 & $* * *$ & \\
\hline RCMAS_CT_MC & $c<---\operatorname{sex}$ & -1.310 & .517 & -2.532 & .011 & \\
\hline
\end{tabular}


Figure 1

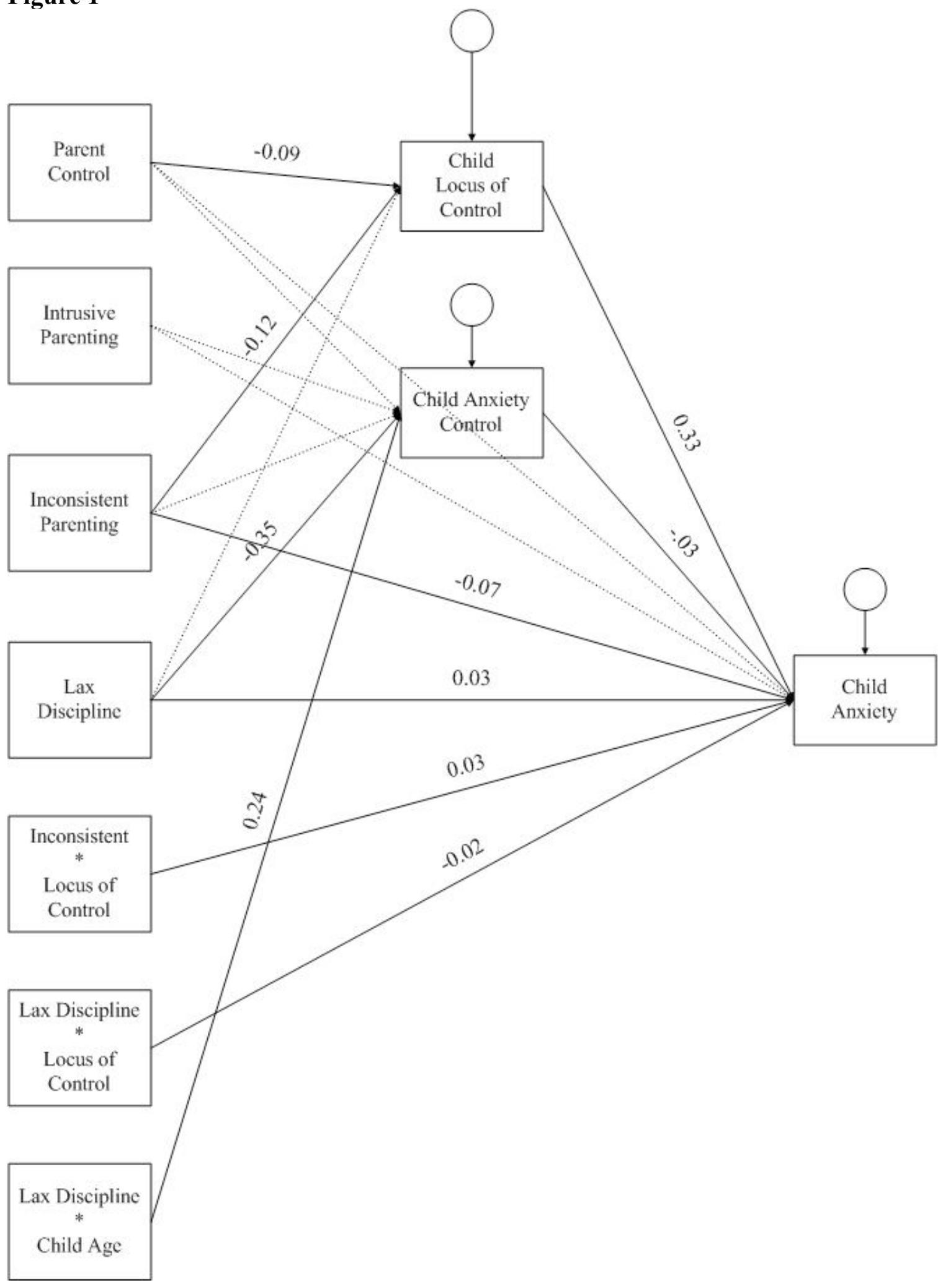

